\title{
Analysis of Correlation and Agreement between the Uroflowmetry and the International Prostate Symptom Score in Patients after retropubic Radical Prostatectomy: A Multicenter Prospective Study*
}

\section{Análisis de correlación y concordancia entre la uroflujometría y la escala internacional de síntomas prostáticos posterior a prostatectomía radical retropúbica: estudio multicéntrico} prospectivo
Lynda Torres $^{10}$ Angie Puerto ${ }^{2}$ Alejandra Bravo ${ }^{3}$
Miguel Acuña ${ }^{4}$ Juan Sánchez ${ }^{4}$ Olga Bejarano ${ }^{1}$
Paula Peña ${ }^{2}$ Juan Guillermo Cataño ${ }^{1}$
Address for correspondence Lynda Torres, MD, Department of Urology, Hospital Universitario San Ignacio, Pontificia Universida, Javeriana, Carrera 7 No.40/62, Unidad de Urología, piso 8, Bogotá D. C., Colombia (e-mail: lynda_torres@javeriana.edu.co; lynda.torresc@gmail.com).

1 Department of Urology, Hospital Universitario San Ignacio, Facultad
de Medicina, Pontificia Universidad Javeriana, Bogotá DC, Colombia
2 Department of Urology, Facultad de Medicina, Pontificia Universidad
Javeriana, Bogotá DC, Colombia
${ }^{3}$ Department of Urology, Hospital Universitario Fundación Santa Fe de
Bogotá and Universidad de los Andes School of Medicine, Bogotá DC,
Colombia
${ }^{4}$ Department of Urology, Fundación Cardioinfantil, Bogotá DC, Colombia

Urol Colomb 2020;29:136-140.

\begin{abstract}
Objectives Patients undergoing retropubic radical prostatectomy (RRP) may suffer from lower urinary tract symptoms (LUTS). We aim to characterize LUTS and to evaluate the correlation and agreement between uroflowmetry and the International Prostate Symptom Score (IPSS) in patients after RRP in two reference centers.

Keywords Methods An observational multicenter prospective study was conducted between

- lower urinary tract December 2015 and September 2016. Patients with at least 12-months of follow-up symptoms after RRP were included; these were evaluated with uroflowmetry and the IPSS.

- prostatectomy

- quality of life Results A total of 90 patients were included. The mean follow-up was of 54.6 months (standard deviation $[S D]=27.52)$, and the mean age was $65(S D=6.85)$ years old. The

- urodynamics

- prostatic neoplasms

- prostatic diseases mean IPSS was $7.41(S D=6.29)$, with $33.3 \%(n=54)$ of the patients with moderate symptoms and $6.7 \%(n=6)$ with severe symptoms. A total of $50 \%(n=45)$ of the patients had normal uroflowmetry. Patients with an abnormal/equivocal result
\end{abstract}

This work was performed at the Hospital Universitario San Ignacio and at the Fundación Cardioinfantil Urology Service, Bogotá, DC, Colombia.

received

March 19, 2019

accepted

July 26, 2019
DOI https://doi.org/

$10.1055 / \mathrm{s}-0039-1697998$.

ISSN 0120-789X.

eISSN 2027-0119.
Copyright $\odot 2020$, Sociedad Colombiana License terms de Urología. Publicado por Thieme Revinter Publicações Ltda., Rio de Janeiro, Brazil. Todos los derechos reservados. 


\section{Resumen}

\author{
Palabras clave \\ - síntomas del tracto \\ urinario inferior \\ - prostatectomía \\ - calidad de vida \\ - urodinámica \\ - neoplasias de la \\ próstata \\ - enfermedades de la \\ próstata
}

in the uroflowmetry had a mean of $9.31(S D=7.03)$ points in the IPSS versus 5.51 $(\mathrm{SD}=4.82)$ in patients with a normal uroflowmetry result $(p<0.01)$. The level of agreement between mild versus moderate-to-severe LUTS and normal uroflowmetry versus abnormal/equivocal was $61.1 \%(\mathrm{k}=0.22, p=0.04)$. We found that a score $\geq 10$ in the IPSS had a level of agreement of $65.6 \%(k=0.31, p=0.0004)$.

Conclusions We consider that although the IPSS cannot replace uroflowmetry and vice versa, these tests are complementary and may be useful tools in the evaluation of patients with LUTS after RRP.

Objetivos Los pacientes en quienes se realiza prostatectomía radical retropúbica (PRR) pueden sufrir de síntomas del tracto urinario inferior (STUIs). El propósito es poder caracterizar STUI y correlacionarlos con la uroflujometría y la Escala Internacional de Síntomas Prostáticos (IPSS por sus siglas en inglés).

Métodos Se realizó un estudio multicéntrico prospectivo entre Diciembre de 2015 y Septiembre de 2016. Se incluyeron todos los pacientes con un seguimiento mínimo de 12 meses después de la PRR. Estos fueron evaluados con uroflujometría e IPSS.

Resultados Se incluyeron un total de 90 pacientes. El seguimiento promedio fue de 54,6 meses (desviación estándar $[D E]=27,52$ ), la edad promedio fue de 65 años (DE $6,85)$. El promedio de la puntuación en la IPSS fue de $7,41(D E=6,29)$ con $33,3 \%$ de los pacientes con síntomas moderados y $6,7 \%$ con síntomas severos. El $50 \%$ de los pacientes tuvieron una uroflujometría normal. Los pacientes con resultado anormal o equívoco en la uroflujometría presentaron un promedio de 9,31 $(D E=7,03)$ en la puntuación de la IPSS, versus $5,51(\mathrm{DE}=4,82)$ en pacientes con una uroflujometría normal $(p<0,01)$. El nivel de concordancia entre los STUls leves y moderados/severos y uroflujometría normal versus anormal/equívoca fue de $61,1 \%(k=0,22, p=0,04)$. Se encontró que un puntaje $\geq 10$ en la IPSS tiene un nivel de concordancia del 65,6\% $(\mathrm{k}=0.31, p=0.0004)$.

Conclusiones Se considera que aunque la IPSS no puede reemplazar la uroflujometría y viceversam, estas pruebas son complementarias, y son herramientas útiles en la evaluación de pacientes con STUls después de la PRR.

\section{Introduction}

Retropubic radical prostatectomy (RRP) is among the alternatives of management with curative intention for localized prostate cancer or for the local control in nonlocalized disease, as it may decrease the risk of progression to metastasis and death associated with this entity. ${ }^{1}$ The objective of the surgery is the control of the disease, preservation of continence and of the sexual function. ${ }^{2}$

Among the complications associated with RRP regarding urinary control is the bladder neck contracture that occurs in 0.5 to $10 \%$ of the patients. Additionally, incontinence can occur due to sphincteric involvement and detrusor hyperactivity in $5 \%$ of the cases. ${ }^{3,4}$ The sphincteric involvement is secondary to the surgical procedure, while hyperactivity is a bladder response to obstruction present in some patients with prostate cancer. $^{3,4}$

However, patients undergoing RRP may suffer from lower urinary tract symptoms (LUTS) different from urinary incontinence(UI). ${ }^{5}$ There are several studies reporting improvement of LUTS after RRP by improving bladder outlet obstruction, while others have reported the development of LUTS by factors inherent to the surgery. ${ }^{6}$

Moreover, LUTS can be generated by factors inherent to the surgery. The pathophysiology of these symptoms may be secondary to the dissection of the posterior urethra, of the bladder neck and of the neurovascular bundles, which induces changes in the lower urinary tract secondary to denervation or ischemic changes during the surgical procedure, in addition to the anatomical changes caused by the urethrovesical anastomosis. ${ }^{7,8}$

The IPSS is a valid and reliable instrument for measuring the severity of LUTS in a subjective way. ${ }^{9}$ Objective tools are also used to complement the results generated by the questionnaire, including noninvasive urodynamic tests, such as uroflowmetry.

To date, the proper way to evaluate LUTS in prostate cancer patients after surgery has not been established. We aim to characterize LUTS and to evaluate the correlation and agreement between uroflowmetry and the IPSS in patients after RRP in two reference centers. 


\section{Methods}

An observational multicenter prospective study was conducted between December 2015 and September 2016. Patients with at least 12-months of follow-up after RRP were included. The study protocol was previously approved by our Institutional Ethics Committee. All of the included patients signed an informed consent before starting the study.

Uroflowmetry and the IPSS were used for the assessment of LUTS. ${ }^{4}$ A maximum urinary flow (Qmax) $\geq 15 \mathrm{ml} / \mathrm{s}$ was interpreted as normal, and $\leq 10 \mathrm{ml} / \mathrm{s}$ as abnormal; it was interpreted as equivocal with a Qmax between 10 and $15 \mathrm{ml} / \mathrm{s}$ or voided volume $(\mathrm{VV})<125 \mathrm{~mL}^{3}$ These last two categories were unified to carry out a bivariate analysis and the analysis of correlation and concordance, and were classified with the purpose of comparing normal versus nonnormal uroflowmetry.

The statistical analysis was performed using STATA 14 software (Statacorp, College Station, TX, USA). We used means and standard deviations (SDs) for quantitative variables; these were analyzed using the Student t-test or the Mann Whitney U-test, according to the distribution of the variables. For categorical variables, we used the chi-squared test. A univariate logistic regression was performed to establish an association between the IPSS and the uroflowmetry; for this analysis, urinary symptoms were classified as the presence of each symptom in $\geq 50 \%$ of the time in the previous month versus $<50 \%$ of the time, reported by the patient.

For nocturia, the presence of $>2$ episodes per night was compared with $\leq 2$. In the case of quality of life, an association was established between feeling delighted, pleased, or mostly satisfied versus feeling indifferent, mostly dissatisfied, unhappy, or terrible with their voiding pattern.

A $p$-value $<0.05$ was considered statistically significant. We evaluated the association between IPSS and the uroflowmetry using the Pearson correlation coefficient ( $r$ ) and the Cohen kappa coefficient $(\mathrm{k})$. The Bonferroni correction was used in the case of multiple comparisons.

\section{Results}

A total of 90 patients with prostate cancer who underwent RRP were evaluated, with a mean follow-up of 54.6 months $(\mathrm{SD}=27.52)$. The mean age was 65 years old $(\mathrm{SD}=6.85)$. At the time of the last control, the mean body mass index (BMI) was $20.6 \mathrm{Kg} / \mathrm{m} 2(\mathrm{SD}=5.09)$.

\section{International Prostate Symptom Score}

All of the patients answered $100 \%$ of the questionnaire. The mean IPSS was $7.41(\mathrm{SD}=6.29) ; 60.0 \%(n=54)$ were asymptomatic or had mild symptoms (IPSS $0-7), 33.3 \%(n=30)$ had moderate symptoms (IPSS 8-19), and 6.7\% $(n=6)$ had severe symptoms (IPSS 20-35).

- Table 1 shows the frequency and severity of the symptoms of the patients. The most frequent and severe symptoms were nocturia, incomplete emptying, and weak stream. In contrast,
Table 1 Severity of urinary symptoms according to the International Prostate Symptom Score

\begin{tabular}{|l|l|l|l|}
\hline Urinary Symptoms & $\mathbf{0 - 1}$ & 2-3 & 4-5 \\
\hline $\begin{array}{l}\text { Incomplete } \\
\text { emptying (n, \%) }\end{array}$ & $63(70.0)$ & $12(13.4)$ & $15(16.6)$ \\
\hline Frequency (n, \%) & $61(67.8)$ & $22(24.4)$ & $7(7.8)$ \\
\hline Intermittency (n, \%) & $82(91.1)$ & $3(3.4)$ & $5(5.5)$ \\
\hline Urgency (n, \%) & $68(75.6)$ & $14(15.5)$ & $8(8.9)$ \\
\hline Straining (n, \%) & $84(93.4)$ & $4(4.4)$ & $2(2.2)$ \\
\hline Weak stream (n, \%) & $59(65.6)$ & $20(22.2)$ & $11(12.2)$ \\
\hline Nocturia (n, \%) & $57(63.3)$ & $15(16.7)$ & $18(20.0)$ \\
\hline
\end{tabular}

the symptoms reported less frequently and with less severity were straining and intermittency. Regarding the quality of life, $63.4 \%$ of the patients reported that they felt very satisfied or delighted with their voiding pattern (-Table 2 ).

\section{Uroflowmetry}

A total of $50 \%(n=45)$ of the patients obtained a normal result in the uroflowmetry. The rest was interpreted as abnormal $(n=11 ; 12.2 \%)$ or equivocal $(n=34 ; 37.8 \%)$. The mean Qmax was $19.87 \mathrm{~mL} / \mathrm{s}(\mathrm{SD}=11.63)$, the mean average flow (Qav) was $11.31 \mathrm{~mL} / \mathrm{s}(\mathrm{SD}=7.02)$, and the mean of $\mathrm{VV}$ was $323.1 \mathrm{~mL}(\mathrm{SD}=183.7)$.

There was an inverse, weak, and statistically significant correlation between the IPSS and the Qmax and Qav ( - Table 3, -Fig. 1).

We also found that patients with an abnormal/equivocal result in uroflowmetry had a mean of $9.31(\mathrm{SD}=7.03)$ points in the IPSS versus $5.51(\mathrm{SD}=4.82)$ in patients with a normal result in the uroflowmetry $(p<0.01)$.

Table 2 Quality of life associated with urinary symptoms

\begin{tabular}{|l|l|}
\hline Personal Statisfaction & $\mathbf{n}(\%)$ \\
\hline Delighted & $14(15.6)$ \\
\hline Pleased & $43(47.8)$ \\
\hline Mostly Satisfied & $15(16.7)$ \\
\hline Indifferent & $4(4.4)$ \\
\hline Mostly dssatisfied & $8(8.9)$ \\
\hline Unhappy & $2(2.2)$ \\
\hline Terrible & $4(4.4)$ \\
\hline
\end{tabular}

Table 3 Correlation coefficient between the uroflowmetry and the International Prostate Symptom Score

\begin{tabular}{|l|l|}
\hline Uroflowmetry parameters & IPSS \\
\hline Qmax $(r, p)$ & $-0.30(0.02)$ \\
\hline Qav $(r, p)$ & $-0.29(0.03)$ \\
\hline VV $(r, p)$ & $-0.26(0.07)$ \\
\hline
\end{tabular}

Abbreviation: IPSS, International Prostate Symptom Score. $r=$ Pearson correlation coefficient; $p=p$ value. 


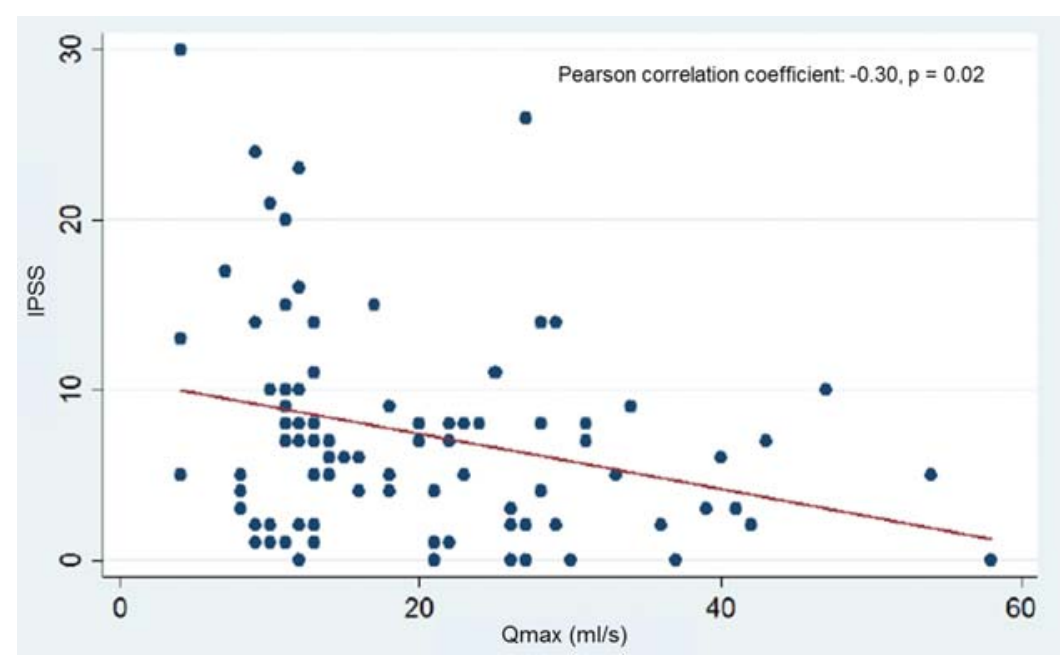

Fig. 1 Scattered plot between the International Prostate Symptom Score and maximum urinary flow (Qmax) with the trend line for linear correlation.

Table 4 Univariate logistic regression analysis to evaluate the association between the International Prostate Symptom Score and the uroflowmetry

\begin{tabular}{|l|l|l|l|}
\hline Urinary Symptoms & OR & $95 \% \mathrm{Cl}$ & -value \\
\hline Incomplete emptying & 3.25 & $1.01-10.44$ & 0.04 \\
\hline Frequency & 2.1 & $0.69-6.40$ & 0.18 \\
\hline Intermittency & 4.29 & $0.44-41.50$ & 0.17 \\
\hline Urgency & 3.32 & $0.93-11.76$ & 0.05 \\
\hline Straining & 1.00 & $0.06-16.77$ & 0.99 \\
\hline Weak stream & 4.53 & $1.11-18.46$ & 0.02 \\
\hline Nocturia & 1.58 & $0.61-4.11$ & 0.34 \\
\hline Quality of life & 0.31 & $0.10-0.99$ & 0.04 \\
\hline
\end{tabular}

Abbreviations: $\mathrm{Cl}$, confidence interval; OR, odds ratio.

Also, feeling delighted, pleased or mostly satisfied with their voiding pattern had an inverse association with the finding of abnormal or equivocal uroflowmetry (-Table 4).

\section{Agreement}

The Pearson correlation coefficient between the IPSS and the Qmax was - $0.30(p=0.02)$ (-Fig. 1), - $0.29(p=0.03)$ between the IPSS and the mean urinary flow rate, and $0.026(p=0.07)$ between the IPSS and VV.

The level of agreement achieved was $61.1 \%(\mathrm{k}=0.22$, $p=0.04$ ) between mild symptoms in the IPSS versus moderate-to-severe symptoms and the results of normal uroflowmetry versus abnormal/equivocal; this agreement was considered acceptable.

In addition, a sensitivity analysis was performed to determine the cutoff point in which the best agreement between the Qmax and IPSS was obtained. We found that a score $\geq 10$ in the IPSS had a level of agreement of $65.6 \%(k=0.31 ; p=0.0004)$.

\section{Discussion}

Few authors have compared LUTS in patients after RRP, given that most studies available in the literature focus on urinary continence. For example, Masters et $\mathrm{al}^{12}$ included a cohort of patients who underwent RRP and were evaluated with uroflowmetry and the IPSS before and after surgery, finding that, after the surgery, two-fifths of the patients had bladder outlet obstruction (BOO), defined as $\mathrm{Qmax}<10 \mathrm{ml} / \mathrm{s}$ associated with bothering symptoms. Additionally, they found a significant increase in the Qmax and a decrease in the IPSS after the surgery. Similar to this study, in the present study we found that $40 \%$ of the patients had moderate-to-severe symptoms, and 50\% had abnormal/equivocal uroflowmetry. In addition, $15 \%$ of the patients felt mostly dissatisfied, unhappy, or terrible with their voiding pattern. This suggests that, despite the fact that most studies report improvement in LUTS after RRP, ${ }^{10}$ the number of patients who continue with symptoms is not negligible and is a problem that should be addressed, considering the important effect on the quality of life suffered by these patients.

Several studies have shown that subjective urinary symptoms have a weak correlation or even have no correlation with objective measures, consistent with the results of our study. ${ }^{17}$ This occurs because the origin of LUTS may have multiple causes, especially in men $>45$ years old, the age at which most of these studies have been performed. Among these other causes, we find bladder dysfunction or urethral stricture. ${ }^{11,15,17}$ Specifically in the case of a patient after an RRP, the incompetent sphincter or urethral stricture of anastomosis can cause these LUTS. However, the urethral stricture can show more correlation between uroflowmetry results and LUTS, since there is outlet obstruction.

A study published by Ezz el Din et $\mathrm{al}^{4}$ with a population of 803 patients found a weak and statistically significant correlation between the IPSS and the result of uroflowmetry, suggesting that better noninvasive tools are needed for the evaluation of these symptoms, which is similar to our results. However, their study focused on patients with LUTS and benign prostatic growth, not on patients with prostate cancer who underwent RRP.

In our study, although the correlation was weak, the agreement was acceptable. Although there are studies that evaluate the agreement between the IPSS and uroflowmetry, 
there are no studies of this correlation in patients after RRP. Considering our results, we believe that performing the uroflowmetry and the IPSS in conjunction can provide relevant clinical information about these patients.

\section{Conclusion}

Most of the patients after RRP were asymptomatic or had mild LUTS, and 50\% had normal uroflowmetry. Patients with an abnormal/equivocal result in the uroflowmetry had a mean IPSS in the range of moderate LUTS compared with patients with a normal uroflowmetry who had a mean IPSS in the range of mild symptoms. The IPSS and the uroflowmetry were inversely and weakly correlated, but the agreement between these tests was acceptable. We consider that although the IPSS cannot replace uroflowmetry, and vice-versa, these tests are complementary and may be useful tools in the evaluation of patients with LUTS after RRP.

Conflicts of Interests

The authors have no conflicts of interests to declare.

\section{Acknowledgments}

We thank our colleagues from Hospital Universitario San Ignacio, Fundación Cardioinfantil and Hospital Universitario Fundación Santa Fé who provided insight and expertise that greatly assisted the research.

\section{References}

1 Holmberg L, Bill-Axelson A, Helgesen F, et al. A Randomized Trial Comparing Radical Prostatectomy with Watchful Waiting in Early Prostate Cancer. N Engl J Med 2002;347(11):781-789. doi:10.1056/ NEJMoa012794

2 Bianco FJ, Scardino PT, Eastham JA. Radical prostatectomy: Longterm cancer control and recovery of sexual and urinary function ("trifecta"). Urology 2005. doi:10.1016/j.urology.2005.06.116

3 McDougal W, Wein A, Kavoussi L, et al. Campbell-Walsh Urology Tenth Edition Review. Saunders: Elsevier; 2012

4 Groutz A, Blaivas JG, Chaikin DC, Weiss JP, Verhaaren M. The pathophysiology of post-radical prostatectomy incontinence: a clinical and video urodynamic study. J Urol 2000;163(06):1767-1770. http://www.ncbi.nlm.nih.gov/pubmed/10799178. Accessed August 5,2018

5 Song C, Lee J, Hong JH, Choo MS, Kim CS, Ahn H. Urodynamic interpretation of changing bladder function and voiding pattern after radical prostatectomy: a long-term follow-up. BJU Int 2010; 106(05):681-686. doi:10.1111/j.1464-410X.2009.09189.x

6 Ahlering TE, Thayer KS, Sumnani D, Hovey RM, Skarecky DW. Radical prostatectomy stabilizes peak urinary flow rates. Can J Urol 2003;10(01):1749-1753. http://www.ncbi.nlm.nih.gov/ pubmed/12625853. Accessed August 5, 2018

7 Gomha M, Boone T. Voiding Patterns In Patients With Post-Prostatectomy Incontinence: Urodynamic And Demographic Analysis. J Urol 2003;169(05):1766-1769. doi:10.1097/01.ju.0000059700.21764.83

8 Giannantoni A, Mearini E, Zucchi A, et al. Bladder and Urethral Sphincter Function after Radical Retropubic Prostatectomy: A Prospective Long-Term Study. Eur Urol 2008;54(03):657-664. doi:10.1016/j.eururo.2007.10.054

9 O'Leary MP. What is the AUA symptom index for BPH, and how is it used? Contemp Urol 1994;6(02):17-23. http://www.ncbi.nlm. nih.gov/pubmed/10151030. Accessed August 5, 2018

10 Ezz El Din K, Kiemeney LALM, De Wildt MJAM, Debruyne FMJ, De La Rosette JJMCH. Correlation between uroflowmetry, prostate volume, postvoid residue, and lower urinary tract symptoms as measured by the international prostate symptom score. Urology 1996;48(03):393-397. doi:10.1016/S0090-4295(96)00206-3

11 Chancellor MB, Blaivas JG, Kaplan SA, Axelrod S. Bladder outlet obstruction versus impaired detrusor contractility: the role of outflow. J Urol 1991;145(04):810-812. http://www.ncbi.nlm.nih. gov/pubmed/2005706. Accessed August 5, 2018

12 Jarvis TR, Chan L, Tse V. Practical uroflowmetry. BJU Int 2012; 110:28-29. doi:10.1111/bju.11617

13 Masters JG, Rice ML. Improvement in urinary symptoms after radical prostatectomy: a prospective evaluation of flow rates and symptom scores. BJU Int 2003;91(09):795-797. http://www.ncbi. nlm.nih.gov/pubmed/12780834. Accessed August 5, 2018

$14 \mathrm{Kim} \mathrm{JH}$, Ha YS, Jeong SJ, Lee DH, Kim WJ, Kim IY. Impact of Robot-assisted Radical Prostatectomy on Lower Urinary Tract Symptoms and Predictive Factors for Symptom Changes: A Longitudinal Study. Urology 2013;81(04):787-793. doi:10.10 16/j.urology.2012.12.038

15 Wadie BA, Ibrahim EHI, De la rosette JJ, Gomha MA, Ghoneim MA. The relationship of the international prostate symptom score and objective parameters for diagnosing bladder outlet obstruction. Part I: When statistics fail. JUrol 2001;165(01):32-34. doi:10.1097/ 00005392-200101000-00008

16 Madersbacher S, Klingler HC, Djavan B, et al. Is obstruction predictable by clinical evaluation in patients with lower urinary tract symptoms? Br J Urol 1997;80(01):72-77. http://www.ncbi. nlm.nih.gov/pubmed/9240184. Accessed August 5, 2018

17 Seki N, Yunoki T, Tomoda T, Takei M, Yamaguchi A, Naito S. Association among the symptoms, quality of life and urodynamic parameters in patients with improved lower urinary tract symptoms following a transurethral resection of the prostate. Neurourol Urodyn 2008;27(03):222-225. doi:10.1002/nau.20466 